GEFAD / GUJGEF41(3): 2217-2250(2021)

\title{
Pedagojik Alan Bilgisine Yönelik Bibliyometrik Bir Araştırma: 1987-2020 Yılları Arasında Yapılan Çalışmaların Analizi*
}

\section{A Bibliometric Research on Pedagogical Content Knowledge: Analysis of Studies Between The Years 1987-} 2020

\author{
Mücahit KÖSE ${ }^{1}$ \\ ${ }^{\text {I} A l a n y a ~ A l a a d d i n ~ K e y k u b a t ~ U ̈ n i v e r s i t e s i, ~ E g ̆ i t i m ~ F a k u ̈ l t e s i, ~ M a t e m a t i k ~ v e ~ F e n ~ B i l i m l e r i ~ E g ̆ i t i m i ~}$ \\ Bölümü.mucahit.kose@alanya.edu.tr.
}

Makalenin Geliș Tarihi: 17.05.2021

Yayına Kabul Tarihi: 27.07.2021

\begin{abstract}
$\ddot{O} Z$
Araştırmanın amacı pedagojik alan bilgisi ile ilgili yayınların bibliyometrik analizini yapmaktır. Bu amaçtan hareketle 1987-2020 ylları arasında Scopus veritabanında taranan 1760 yayın bibliyometrik açıdan incelenmiş ve son 34 yıldaki eğilim ortaya konmuştur. Veri tabanında "pedagogical content knowledge" anahtar kavramı kullanılarak tarama gerçekleştirilmiş ve yıllara ilişkin yayın sayısı, bu konuda en çok yayın yapan dergiler ve yazarlar, yazarların $h$ indeksleri, sorumlu yazarların ülkeleri ve işbirliği ağları, en çok atıf alan yayınlar, yıllık ortalama alıntı sayısı, yazarların atıf patlama değerleri, kelime bulutu, kelime ağacı haritası ve kavramsal yapı haritası alt başlıklarında incelenmiştir. Elde edilen sonuçlara göre konuya olan ilginin 2002 yllından itibaren arttı̆̆ söylenebilir. Bu konudaki makalelerin en fazla yayınlandiğ dergi International Journal of Science Education olup, S. Blömeke, G. Kaiser ve M. Rollnick'in bu alanda en fazla makale yazan yazarlar olduğu belirlenmiştir. Pedagojik alan bilgisi en fazla fen ve matematik alanında çalışılmıştır. En fazla oranda Pedagojik alan bilgisinin yapısı, geliştirilmesi ve diğer bilgi türleriyle ilişkileri üzerine araştırmaların gerçekleştirildiği görülmektedir. Brezilya ve Kore'deki araştırmacıların işbirliğine en açık araştırmacılar olduğu belirlenmiştir. Makalelerin keyword ve özet kısmında en çok kullanılan kavramların sırasıyla "teaching", "pedagogical content knowledge"," student" ve "education" olduğu tespit edilmiştir. Elde edilen sonuçların bu konuda araştırma yapmak isteyen araştırmacılara ışık tutacă̆ına inanılmaktadır.
\end{abstract}

\footnotetext{
*Alıntılama: Köse, M. (2021). Pedagojik alan bilgisine yönelik bibliyometrik bir araştırma: 1987-2020 yılları arasında yapılan çalışmaların analizi. Gazi Üniversitesi Gazi Eğitim Fakültesi Dergisi, 41(3), 2217-2250.
} 
Anahtar Kelimler: Pedagojik alan bilgisi, Bibliyometrik analiz, R-Stüdyo, Öğretmen eğitimi

\begin{abstract}
The aim of this study is to conduct a bibliometric analysis of the publications related to pedagogical content knowledge. 34 years of pedagogical content knowledge research between 1987-2020 is analyzed through bibliometric research. The descriptive research model has been adopted for this bibliometric study and the bibliometric properties of the articles, books, and book chapters are determined by using the keyword of "Pedagogical content knowledge" in the Scopus database. The number of publications per year, the most published journals and authors, $h$ indexes of the authors, the countries and cooperation networks of the responsible authors, the most cited publications, the average number of citations per year, citation burst values of the authors were examined under word cloud, word treemap and conceptual structure map subtitles. According to the results, it can be said that the interest in the subject has increased since 2002. The journal with the highest number of articles on this subject was the International Journal of Science Education, and it was determined that S.Blömeke, G.Kaiser, and M. Rollnick were the authors who wrote the most articles in this field. The topics of the articles in this field are mainly on the structure, and development of Pedagogical content knowledge and its relations with other types of knowledge have been carried out at the highest rate. Pedagogical content knowledge has been studied mostly in the fields of science and mathematics. It has been determined that researchers in Brazil and Korea are most open to collaboration. It has been determined that the most frequently used concepts in the keyword and summary part of the articles are "teaching", "pedagogical content knowledge", "student" and "education", respectively. It is believed that the results obtained will shed light on researchers who want to research this subject.
\end{abstract}

Keywords: Pedagogical content knowledge, Bibliometric analysis, R-studio, Teacher education 


\section{GİRiş}

Öğretmen, eğitim ve öğretimin önemli unsurlarından birisidir. Bu nedenle eğitim ve öğretimde istenilen amaçlara ulaşılmasında öğretmenlerinde istenilen niteliklerde gerekli bilgi ve becerilere sahip olmaları beklenir. Nitekim güncel gelişmeler ve çağın gereksinimleri doğrultusunda nasıl ki eğitim hedefleri ve öğretim programlarında değişikliklere gidilmekteyse öğretmen yetiştirme programları da güncellenmekte bunun yanısıra görev yapmakta olan öğretmenlerin gelişimleri için hizmet için eğitimler gerçekleştirilmektedir. $\mathrm{Bu}$ bağlamda öğretmen yeterliliklerinin eğitimciler ve araştırmacılar için önemli bir araştırma alanı olduğu söylenebilir. Öğretmenlerin yeterlilikleri kapsamında öğretmenlerin sahip oldukları bilgilerinin nitelik ve niceliği öğretmen yetiştirmede önem arz eder. Bu bağlamda pedagojik alan bilgisi araştırmaları öğretmen eğitiminde önemli bir araştırma alanı olmuştur. Pedagojik alan bilgisinin yapsının belirlenmesi pedagojik alan bilgisinin geliştirilmesine katkı sağlayacağı ve bu durumun da öğretmen eğitiminde ve dolayısıyla öğretmen niteliklerini iyileştirmede önemli olacağı söylenebilir. Bu nedenle uzun yıllardır Pedagojik alan bilgisinin yapısı araştırmacılar tarafından farklı şekillerde açıklanmış, tanımlanmış ve hâlen de araştırılmaya devam edilmekle birlikte araştırmacıların oldukça ilgisini çeken bir çalışma alanı olmuştur (Abel, 2008; Loughran vd., 2004).

Pedagojik alan bilgisi ilk defa Lee Shulman (1986) tarafindan konu alan bilgisi ve müfredat bilgisiyle birlikte alan bilgisinin türlerinden birisi olarak vurgulanmış ve bir konunun anlaşılmasını sağlamak için kavramları en iyi şekilde temsil eden analojiler, örnekler, açıklamalar, sunumlar ve gösteri yöntemleri hakkındaki bilgidir şeklinde tanımlanmıştır. Bir yıl sonra Shulman (1987); (i) Konu alan bilgisi, (ii) Genel pedagojik bilgi (iii) Öğretim programı bilgisi, (vi) Öğrenenler ve onların özellikleri bilgisi, (v) Bağlam bilgisi, (vii) Eğitim hedefleri, amaçları, değerleri, tarihi ve felsefi temelleri bilgisinden oluşturduğu öğretmenliğin bilgi temeline; (vii) Pedagojik alan bilgisini eklemiştir. Pedagojik alan bilgisinin; öğrenciler ve özellikleri hakkında bilgi, öğrencilerin fiziksel, zihinsel, sosyal, duygusal, dilsel ve psikolojik gelişim dönemlerini, 
onların zihinsel ve sosyal yapılarının işleyişini, ilgi ve gereksinimlerini, nasıl daha iyi öğrenebilecekleri gibi bilgilerden oluştuğunu ifade etmiştir.

Daha sonraki yıllarda hem öğretmenlerin sahip oldukları bilgi türleri hem de pedagojik alan bilgisinin yapısı araştırmacılar tarafından farklı modellerle ve araştırmalarla açıklanmaya çalışılmıştır. Tamir (1988), PAB boyutlarına Shulman (1987)'dan farklı olarak değerlendirmeyi de eklemiştir. Grosman (1990) öğretmenlerin sahip oldukları meslek bilgilerini pedagojik alan bilgisi, genel pedagoji bilgisi, bağlam bilgisi ve konu alan bilgisi olarak açıklamış; pedagojik alan bilgisini öğrencilerin anlaması ve kavramasıyla ilgili bilgi, öğretim programı bilgisi, öğretim yöntemleri bilgisi ve öğretimin amaçları bilgisi olmak üzere dört alt başlıkta toplamıştır. Cochran, Deruiter ve King (1993) öğretmenin öğreteceklerine dair bilgisi ile öğretime ilişkin bilgisini birleştirmesiyle pedagojik alan bilgisini oluşturduğunu, oluşturulan bilginin durağan bir yapıda olmamasından, sürekli gelişmekte olmasından dolayı bu bilgiyi pedagojik alanı bilme olarak ifade etmiş, alan bilgisi, öğrenci bilgisi, pedagoji bilgisi ve çevresel bağlamın kesişiminden ve etkileşimden ortaya çıktığını vurgulamıştır. Carlsen (1999), öğretmen bilgisini; konu alan bilgisi, genel eğitim bağlamı hakkındaki bilgi, özel eğitim bağlamı hakkındaki bilgi, genel pedagoji bilgisi ve pedagojik alan bilgisi olarak; pedagojik alan bilgisini ise alan eğitimine yönelik amaçlar, öğrenci yanlı̧ kavramaları, konuya özgü öğretim stratejileri ve alan öğretim programı bilgilerinin oluştuğunu belirtmiş̧ir. Gess-Newsome (1999) ise pedagojik alan bilgisini bütünleyici ve dönüştürücü iki modelle açıklamıştır. Bütünleyici modelde pedagojik alan bilgisi ayrı bir bilgi alanı olarak yer almayıp konu alan bilgisi, pedagoji bilgisi ve bağlam bilgisinin kullanıldığını belirtmiştir. Dönüştürücü modelde ise pedagojik alan bilgisi bu bilgilerin sentezinden oluşmaktadır. Veal ve MaKinster (1999), pedagojik alan bilgisini; genel, alana özgü ve konuya özgü olarak sınıflandırmıştır. Magnusson, Krajcik, Borko (1999)'un genelikle fen eğitimi araştırmalarında tercih edilen modellerinde PAB; öğretime yönelik oryantasyon, öğretim program bilgisi, öğretim stratejileri bilgisi, öğrenci bilgisi ve değerlendirme bilgilerinden oluşmaktadır. Abel (2007); Magnusson vd. (1999) ile Grossman (1990)'ın modellerini birleştirerek PAB'1 oryantasyon, 
öğrenenler bilgisi, öğretim program bilgisi, öğretim yöntemleri bilgisi ve değerlendirme bilgisi bileşenlerinden oluşan bir yapıyla açıklamış aynı zamanda PAB'ın konu alan bilgisi, pedagojik bilgi ve bağlamla ilgili bilginin etkisiyle şekillendiğini dile getirmiştir. An, Kulm ve Wu (2004) konu alan bilgisi, öğretim bilgisi, program bilgisi ve öğretmen inançlarını PAB boyutları olarak belirttiği modelinde öğrencilerin düşünme yapılarını öğretim bilgisinin alt boyutu olarak yapılandırmıştır.

Ball, Thames ve Phelps (2008) matematik eğitimi alanında matematiği öğretme bilgisini; konu alanı bilgisi ve pedagojik alan bilgisi olmak üzere iki bileşenle yapılandırmıştır. Konu alanı bilgisini; genel, uzmanlık ve kapsamlı alan bilgisi olmak üzere üç bileşenle, pedagojik alan bilgisini ise alan ve öğrenci bilgisi, alan ve öğretme bilgisi ile alan ve program bilgisi bileşenleriyle açıklamıştır. Araştırmacılar tarafından pedagojik alan bilgisinin farklı biçimlerde yapılandırıldığı görülmektedir.

Gerçekleştirilen araştırmalarda pedagojik alan bilgisinin bazı araştırmalarda tüm bileşenlerin birlikte incelendiği (Lee ve Luft, 2008; Mavhunga ve Rollnick, 2011) bazılarında ise (Berg ve Brouwer, 1991; Friedrichsen ve Dana, 2003; Sande, 2010) tüm bileşenler yerine belirli bileşenlere odaklanıldığı görülmektedir. PAB bileşenleriyle ilgili olarak birçok araştırmacı tarafından ayrı bir bileşen olarak ele alınmayan oryantasyon bileşeniyle ilgili olarak; Magnusson, Krajcik, Borko (1999); oryantasyon bileşeninin diğer tüm bileşenleri etkilediğini, şekillendirdiğini belirtmektedir (Veal ve MaKinster (1999); Öğrenci bilgisinin diğer PAB bileşenlerine oranla pedagojik alan bilgisini etkilemekte daha ön planda olduğunu ve öğrenci bilgisi öğrenilmedikçe diğer PAB özelliklerinin gelişebilmesinin mümkün olmadığını belirtmiştir. Loughran vd. (2006)'da PAB'ın deneyimle zaman içerisindeki gelişimine vurgu yaparken bilgiyi öğrenciler için anlamlandırmayı vurgulamıştır.

Pedagojik alan bilgisinin yapısının belirlenmesinde araştırmacıların odaklandığı noktalardan birisi de alan bilgisi olmuştur. Shulman (1986) alan bilgisini, öğretmenin zihnindeki bilginin miktarı ve onun düzenlenmesi olarak tanımlamıştır. Mishra ve Koehler (2006) ise "öğrenilmesi veya öğretilmesi gereken asıl konu ile ilgili bilgi” olarak tanımlamıştır. İyi bir pedagojik alan bilgisine sahip olmak için öncelikle iyi bir 
alan bilgisine sahip olması gerektiği belirtilmektedir (Even, 1993; Veal ve MaKinster 1999).

Pedagojik alan bilgininin yapısını açıklamaya çalışan araştırmaların yanı sıra öğretmenlerin (Drechsler ve Van Driel, 2008; Monet, 2006; Rollnick ve Mavhunga 2014) ya da öğretmen adaylarının (De Jong ve van Driel, 2004; Nilsson ve Loughran, 2011; Mavhunga ve Rollnick, 2013) PAB'larını geliştirmeye yönelik araştırmalarda lteratürde yer almaktadır. Cochran, King ve DeRuiter (1991), öğretmen adaylarının ve öğretmenlerin pedagojik alan bilgilerinin farklılaştığını belirtmiştir.

Morine-Dershimer ve Kent (1999) pedagojik alan bilgisinin birçok bilgiden etkilendiğini belirtirken bu bilgi türlerini şu şekilde sıralamıştır; öğrenme ve öğrenci, pedagoji, öğretim programı, alan, özel bağlamlar ve değerlendirme süreçleri, sonuçların değerlendirilmesi, eğitsel amaçlar, hedefler ve değerler bilgileri. Pedagojik alan bilgisinin etkilendiği bilgi türleri dikkate alındığında pedagojik alan bilgisinin sınırlarına karar vermenin zor olduğu görülmektedir (Marks, 1990). Pedagojik alan bilgisinin konuya, bağlama ve kişiye özgü olması bu bilgi türünün benzersiz bir doğaya sahip olmasina neden olmaktadır (Cooper vd., 2015; Park ve Suh, 2015; Sande, 2010). Bu bağlamda da pedagojik alan bilgisi konu alanının yapılan birçok araştırmaya rağmen hâlen araştırılabilir ve keşfedilebilir bir doğada olduğunu söylemek mümkündür. Matematik ve fen eğitimi alanları başta olmak üzere birçok alanda pedagojik alan bilgisi araştırmaları yapılmaya devam edilmektedir.

$\mathrm{Bu}$ alanda çalışan araştırmacılar için yapılan bilimsel araştırmalara ulaşmak, öncülük yapan araştırmacıları tanımak ve yaptıkları çalışmaları incelemek önem arz etmektedir. $\mathrm{Bu}$ noktadan yola çıkarak bu araştırmanın amacı pedagik alan bilgisi konusunda araştırma yapan ve literatürde önde gelen araştırmacıları ve yayınlarını tanıtmak, bu konuda yayın basan dergileri sunmak, konu taramasında sıklıkla kullanılan anahtar kelimeleri tanıtmaktır. Literatürde bu konuya yönelik bir araştırmaya rastlanmamış olup, sonuçların araştırmacılara rehber olacağına inanılmaktadır. $\mathrm{Bu}$ amaçla bibliyometrik bir araştırma yoluyla 1987-2020 yılları arasındaki pedagojik alan bilgisi araştırmalarının 34 yıllık süreci analiz edilmiştir. Bibliyometrik araştırma, farklı 
çalışmaları bibliyografik olarak analiz etmeye dayanmaktadır. Bibliyometrik analiz mevcut bilgileri özetlemeye ve yorumlamaya yardımcı olan bir yöntemdir. Literatürde çok sayıda bibliyometrik araştırma (Aman ve Butto, 2017; Doğru, Güzeller ve Çelik, 2019; Fix, Odell, Sina, Meslin, Goodman, \& Upshur, 2013; Kurtuluş ve Bilen, 2021; Kurtuluş ve Tatar, 2021a, 2021b; Lin ve Lei, 2020; Lopes, Fidalgo-Neto ve Mota, 2017; Taner, Kurtuluş ve Bilen, 2021) yer almaktadır.

\section{YÖNTEM}

Betimsel araştırma modelinin benimsendiği bu araştırmada, Scopus veri tabanında "Pedagogical content knowledge" anahtar kelimeleri kullanılarak, dergilerinde yer alan makalelerin, kitap ve kitap bölümlerinin bibliyometrik özellikleri belirlenmiştir. Betimsel araştırmalarda gerçekleştirilen bibliyometrik analizler, kaynakların kendi iç değerlendirmelerini yapmayı sağlayarak bilimsel yayın politikalarını yönlendirmeye olanak sağlar. Ayrıca araştırmacıların çalışma yaptıkları konu alanlarına yönelik bilgi edinmelerine firsat sunar (Al, Soydal ve Yalçın, 2010). Bibliyometrik analiz; ülkeleri, kurumları, konu alanlarını, dergileri, özel araştırma konularını belirleme ve değerlendirmede oldukça etkili bir yöntemdir (Huang, Ho ve Chuang, 2006).

\section{Örnekleme}

Araştırma verilerini Scopus veri tabanında 1987-2020 yılları arasında farklı dergilerde ve kitaplarda yayınlanan "pedagogical content knowledge" anahtar kavramlarıyla ilişkili makaleler, kitap ve kitap bölümleri oluşturmaktadır. Veri tabanı taramasında konu alanına ilişkin olarak, review çalışmalar, editorial material ve letter doküman türleri incelemeye dâhil edilmemiştir. Araştırma kapsamında taranan konu alanına yönelik olarak elde edilen veriler sonucunda, veri tabanındaki ilk araştırmanın 1987 yılında yayınlanmış olması sebebiyle başlangıç tarihi olarak bu tarih seçilmiştir. 2021 yılının henüz tamamlanmaması sebebiyle analizi etkileyeceği düşünüldüğünden bu yıla ilişkin çalışmalar dâhil edilmemiştir. Bibliyometrik çalışmalarda en önemli veri kaynakları Science Citation Index (SCI), Social Science Citation Index (SSCI) ve Art \& 
Humanities Citation Index (A\&HCI) olmak üzere uluslararası atıf indeksleridir. Bu bağlamda bu indekslere ulaşım sağlayan veri tabanlarından birisi olması (Güzeller ve Çeliker, 2017) ve R-Studio programı üzerinden çalıştırılan bibliyometrik analiz sisteminin bu veri tabanıyla da uyumlu olması sebebiyle Scopus veri tabanı üzerinden araştırma gerçekleştirilmiştir.

\section{Verilerin Toplanması}

Araştırmada "Pedagogical content knowledge" anahtar kavramlarıyla tarama yapılmış ve veri tabanında toplam 2024 çalışmaya ulaşılmıştır. Araştırmada pedagojik alan bilgisi araştırmalarına odaklanmak amaçlandığından "technological pedagogical content knowledge" anahtar kavramı çıkarılarak teknolojik pedagojik alan bilgisi çalışmaları örneklem kapsamından çıkarılmıştır. Araştırmanın amacı bağlamında yayın türü ve zaman aralığı kısıtlamaları yapılarak toplamda 1760 makale, kitap ve kitap bölümüne ulaşılmıştır. Bu 1760 yayının yıllara göre dağılımına, ortalama alıntı sayısına, en çok yayın yapılan dergilere, en çok yayın yapan yazarlara, yazarların atıf patlama değerlerine, h-indekslerine, ülkelerin bilimsel üretkenliğine, en çok atıf yapılan kaynaklara, işbirliği ağlarına, kelime bulutu, kelime ağacı haritalarına ve kavramsal yapılara ulaşılmıştır.

\section{Veri Analizi}

Araştırma kapsamında taranan yayınlara ilişkin bulguların elde edilmesinde R-Studio programından yararlanılmıştır. R ortamı, bibliyometrik analizler için kullanılan birçok paketi resmi deposu olan https://cran.r-project.org/ üzerinden sağlamaktadır. Bibliyometride kullanılan bu paket programlar nicel araştırmalar için oldukça faydalıdır (Aria ve Cuccurullo, 2017). Bibliyometrik analizlerde R programının kullanılması daha fazla bulguya ve ayrıntılı gösterime sahip olması sebebiyle seçilmiştir.

Scopus veri tabanından araştırmanın ölçütlerine göre hazırlanan çalışmanın veri dosyası için sırasıyla; "All" seçeneği tıklanmıştır, export, bibtex, "citation information, bibliographical information, abstract \& keywords, funding details, other information" seçenekleri tıklanarak export edilmiş̧ir. Daha sonra R-Studio programı üzerinden 
"bibliometrix" paketi indirilip aktif hâle getirilmiştir. R-Studio üzerinden "bibliometrix" paketi çalıştırılmıştır. Daha sonra R-Studio programı bir adres üzerinden bibliyometri analizi sayfasına yönlendirmiştir. Burada "bibtex" dosyası data (veri) kısmına yüklenerek analizler gerçekleştirilmiştir. Çalışmaya ilişkin diyagram Şekil-1'de yer almaktadir.

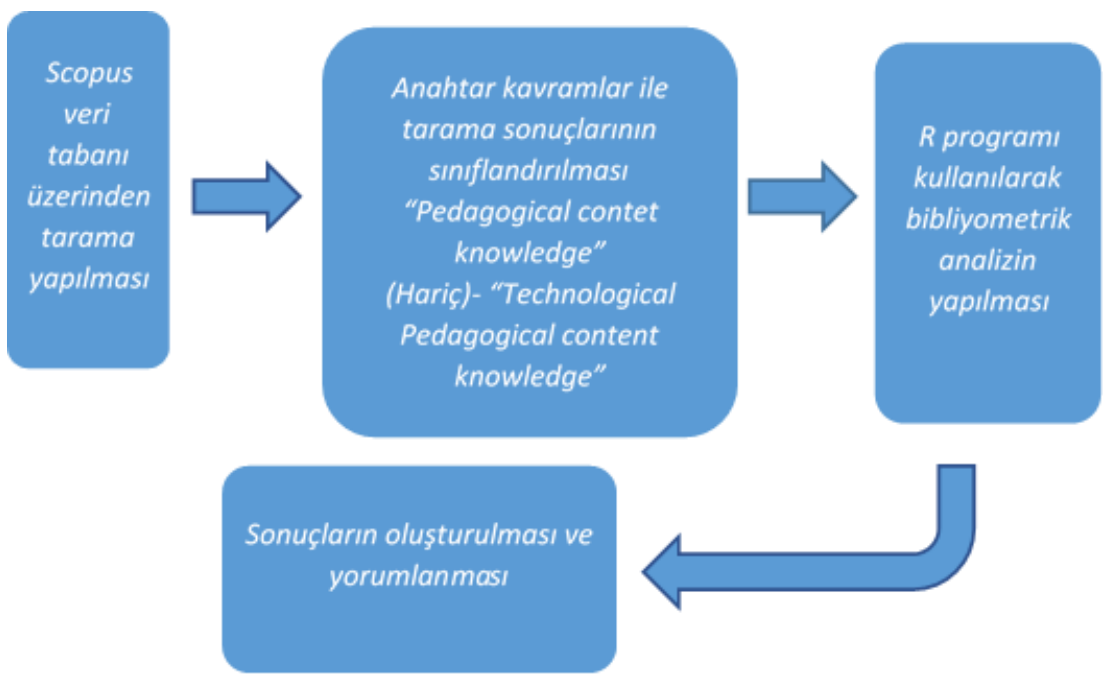

Şekil 1. Çalışma Diyagramı

\section{Etik Kurallara Uygunluk}

"Pedagojik alan bilgisine yönelik bibliyometrik bir araştırma: 1987-2020 yılları arasında yapılan çalışmaların analizi" başlıklı araştırmada Scopus veri tabanı üzerinden gerçekleştirilen tarama sonucunda belirlenen yayınların erişime açık verilerinden yararlanılmıştır. Açık erişim verileri kullanıldığından etik kurul izni gerekli bulunmamıştır. Araştırmanın tüm süreçlerinde etik kurallara uyulmuştur. Çalışmada yararlanılan tüm kaynaklara atıfta bulunulmuştur. 


\section{BULGULAR}

Pedagojik alan bilgisi ile ilgili toplam 1760 yayına ait bilgiler yıllara göre Tablo-1'de sunulmuştur.

Tablo 1. Yıllara İlişkin Yayın Sayısı

\begin{tabular}{lll}
\hline Yıl & Yayın Sayısı (f) & Yüzde (\%) \\
\hline $1987-1991$ & 13 & 0.74 \\
$1992-1996$ & 29 & 1.64 \\
$1997-2001$ & 45 & 2.55 \\
$2002-2006$ & 108 & 6.14 \\
$2007-2011$ & 283 & 16.08 \\
$2012-2016$ & 637 & 36.20 \\
$2017-2020$ & 645 & 36.65
\end{tabular}

Tablo-1 incelendiğinde PAB ile ilgili eserlerin 1987 yılında yayınlanmaya başladığı, ilgili alanda en fazla yayının 2017-2020 yılları arasında (f=645) yapıldığı görülmektedir. 2011 yılından sonra yayınlanan eserlerin toplamın \%72.85'ini oluşturduğu görülmektedir. Konu alanına yönelik olarak ortalama alıntı sayısı Grafik1 'de gösterilmiştir.

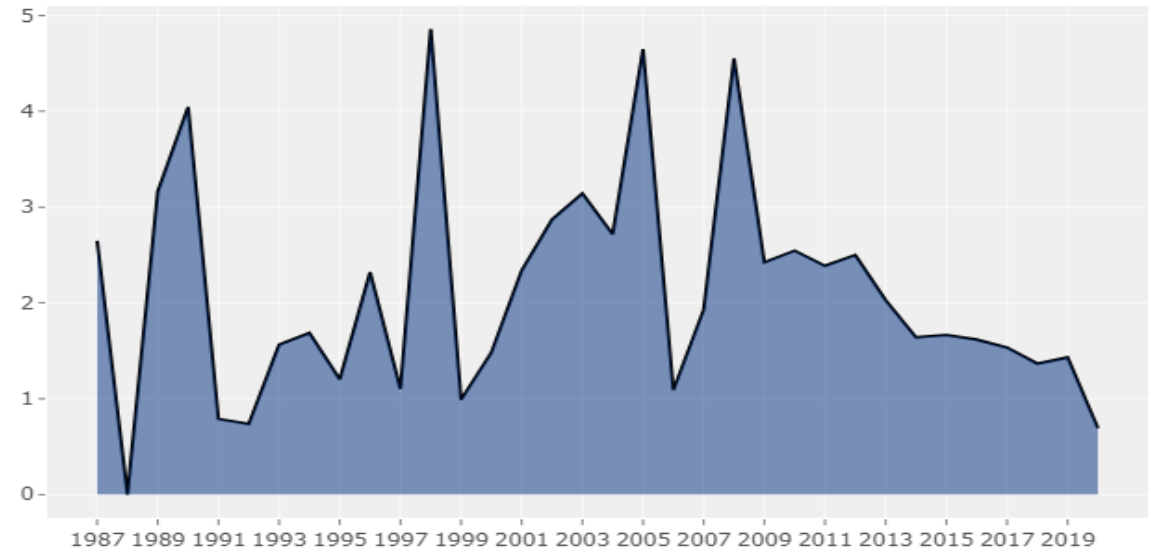

Grafik 1. Y1llık Ortalama Alıntı Sayısı 
Grafik-1 incelendiğinde yıllık ortalama alıntı sayısının en fazla 1998 yılında gerçekleştiği görülmektedir. Grafik-2 merkeze alınan anahtar kavrama göre yazarların hangi dergide yayın yaptı̆̆ını göstermektedir.

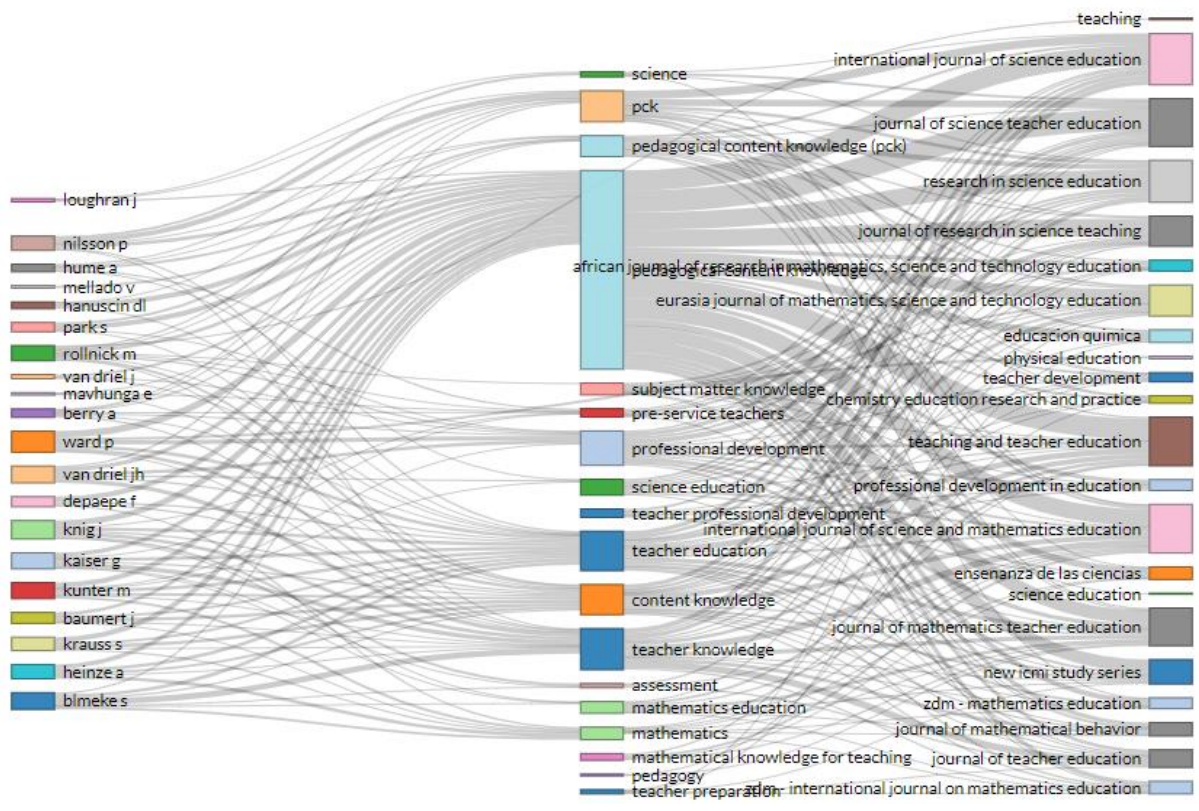

Grafik 2. Üç Alan Grafiğgi

Grafik-2 incelendiğinde yazarların çoğunun "pedagogical content knowledge" kavramını kullanarak grafikte yer alan tüm dergilerde yayın yaptığı görülmektedir. Araştırmacıların çoğunun "teacher education" anahtar kavramını da kullanarak dergilerde yayın yaptıkları görülmektedir. Grafik-3'te en fazla yayının yapıldığı ilk 20 dergi gösterilmektedir. 

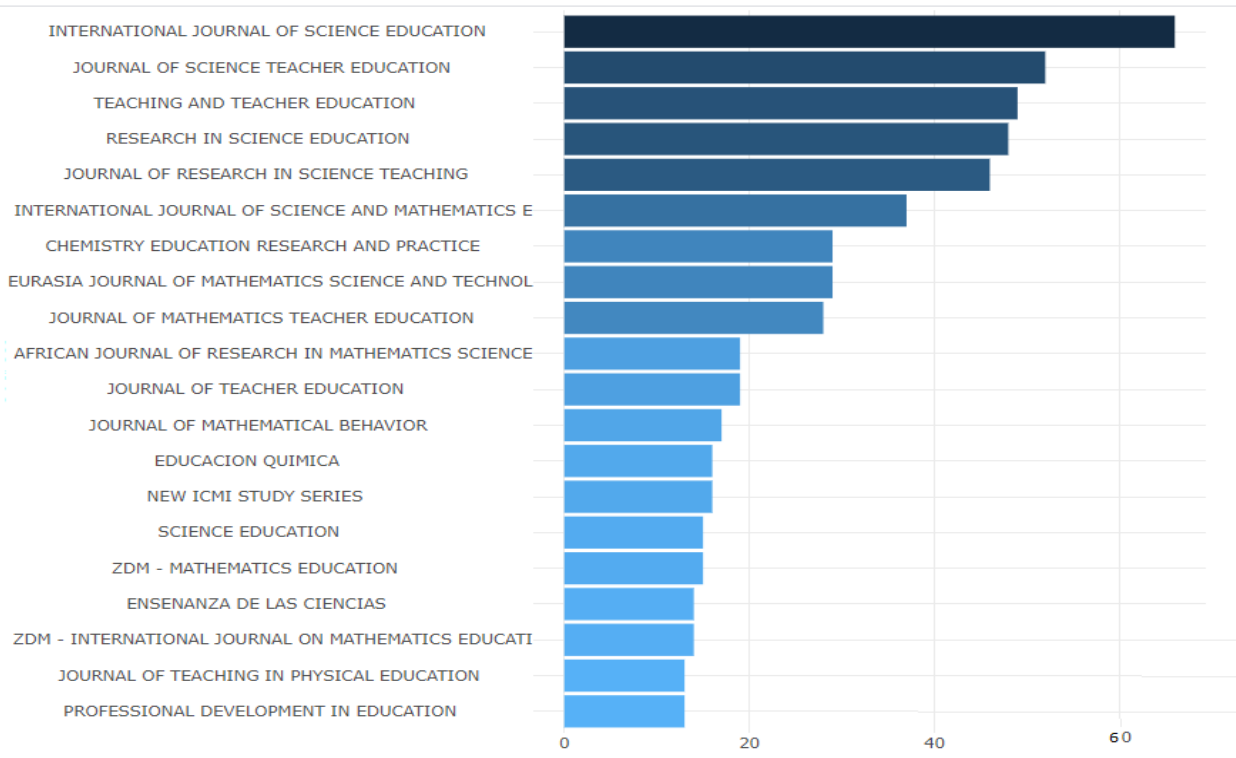

Grafik 3. Konu Alanına Yönelik En Çok Yayın Yapan Dergiler

"Pedagogical content knowledge" anahtar kavramı taratılarak bulunan makalelerin en fazla yayınladığı dergilerin International Journal of Science Education ( $\mathrm{f}=66$ ), Journal of Science Teacher Education ( $\mathrm{f}=52$ ) ve Teaching and Teacher Education ( $\mathrm{f}=49$ ) olduğu görülmektedir. Grafik-4'te konu alanıyla ilgili olarak en fazla makale yazan yazarlar yer almaktadir. 


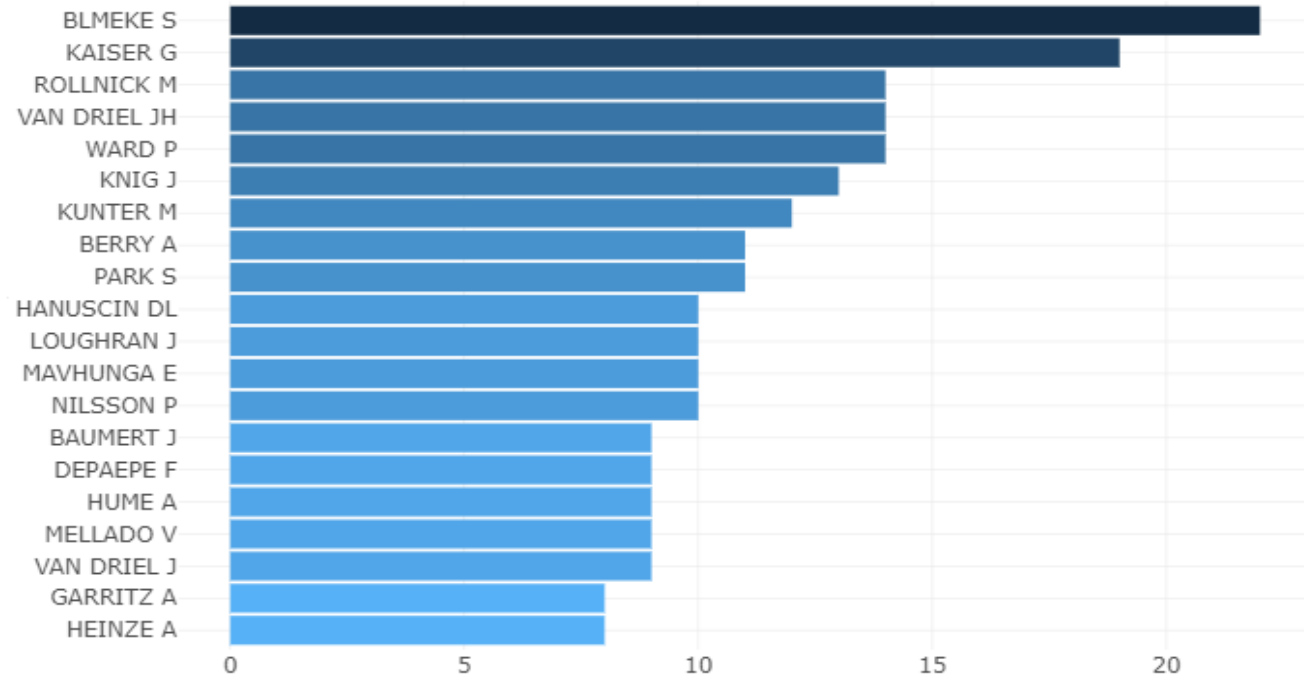

Grafik 4. Konu Alanına Yönelik En Çok Yayın Yapan Yazarlar

Grafik-4 incelendiğinde Konu alanıyla ilişkili işbirlikli ya da bireysel olarak toplam 1760 yayının yaptığı tespit edilmiştir. Yazar başına düşen makale sayısına bakıldığında oranın 0.543, makale başına düşen yazar sayısına bakıldığında ise 1.84 olduğu tespit edilmiştir. PAB konusunda en fazla makale yazan yazarların S. Blömeke ( $f=21$ ), G. Kaiser ( $f=19$ ) ve M. Rollnick ( $f=14)$ olduğu görülmektedir. Araştırmacılardan ilki Norveç'de University of Oslo ikinci araştırmacı Almanya'da University of Hamburg, son araştırmacı ise Güney Afrika'da University of Witwatersrand'de görev yapmaktadırlar. Grafik-5'te yazarların atıf patlama değerlerine yer verilmiştir. 


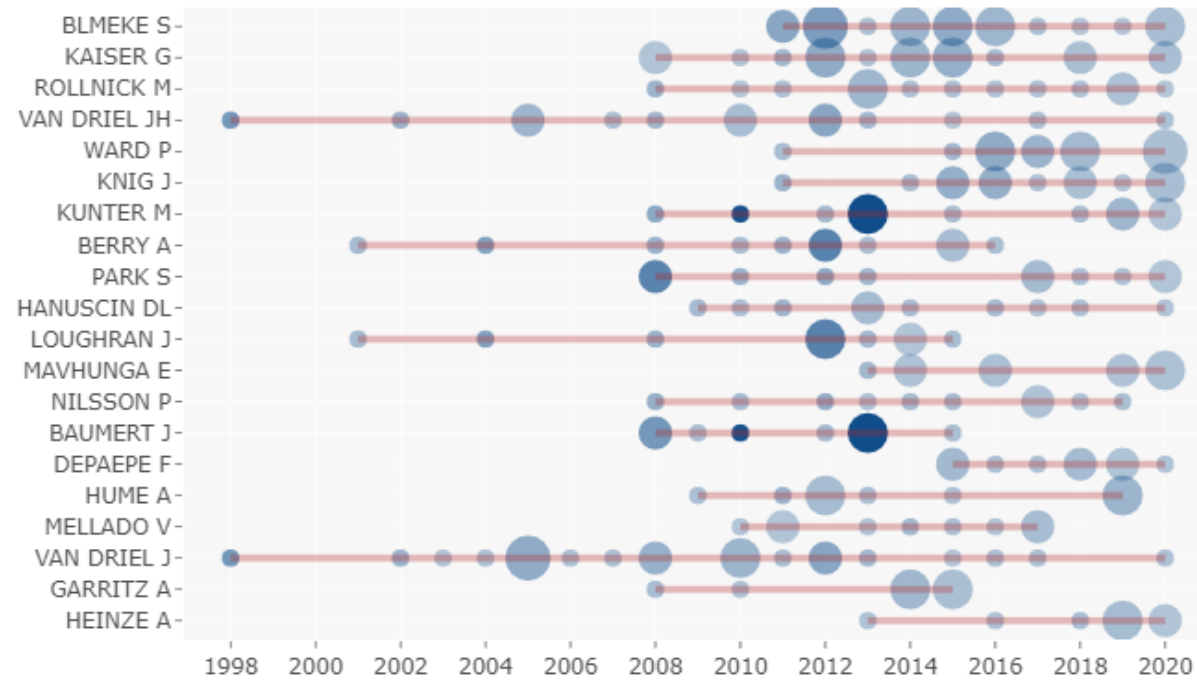

Grafik 5. Atıf Patlama Değerleri

Yazarların atıf patlama değerlerine (burst) bakıldığında, en yüksek atıf patlamasına sahip yazarlar 2008-2020 yılları aralığında M. Kunter (60.89) ve 2008-2015 yılları arasında J. Baumert'dir. Kunter ve Baumert en fazla atıf alan yazarlar olmayabilirler bu durum atıf patlama değerini oluşturan yıl içerisinde en çok atıf almasından kaynaklanmaktadır. J. Van Driel ve J.H. Van Driel isimli yazarların 1998-2020 yılları arasındaki 22 ylllık süreçte alana yön veren isimler konumunda olduğu görülmektedir. Bu durum 1998-2020 yılları arasında kesintiz olarak atıf almalarından anlaşılmaktadır. Tablo-2'de en fazla atıf patlama değerine sahip ilk dört yazar yer almaktadır.

Tablo 2. Yazarlara Göre Atıf Patlama Değerleri ve Başlangıç-Bitiş Aralı̆̆ı

\begin{tabular}{llll}
\hline Yazarlar & Patlama & Başlangıç & Bitiş \\
\hline M.Kunter & 60.89 & 2008 & 2020 \\
J.Baumert & 60.89 & 2008 & 2015 \\
J.Loughran & 34.20 & 2001 & 2015 \\
A.Berry & 33.60 & 2001 & 2016 \\
\hline
\end{tabular}


Tablo 2'de yer alan isimlere bakıldığında yazarların yüksek atıf patlama değerlerine sahip oldukları dikkati çekmektedir. Grafik-6'da sorumlu yazarların ülkeleri yer almaktadir.

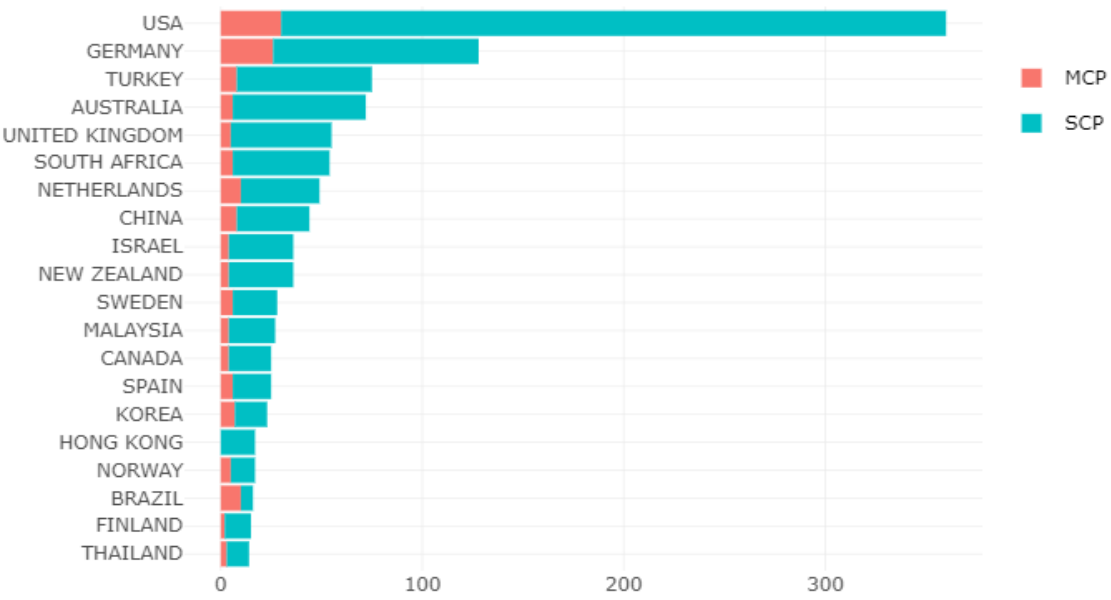

Grafik 6. Sorumlu Yazarların Ülkeleri ve Makale Sayısı

Grafik-6 incelendiğinde çalışmayı gerçekleştiren sorumlu yazarların ülkeleri görülmektedir. SCP (Single Country Publications) olarak adlandırılan bölüm aynı ülkedeki araştırmacıların yaptıkları yayın sayısını, MCP (Multiple Country Publications) olarak adlandırılan bölüm ise birden fazla ülkedeki araştırmacıların birlikte yaptıkları yayınları göstermektedir. Sorumlu yazarların ülkelerine bakıldığında toplamda 360 makaleyle ABD (SCP: 330, MCP:30), 128 makaleyle Almanya (SCP:102, MCP:26) ve 75 makaleyle Türkiye (SCP: 67, MCP: 8) ilk üç sırada yer almaktadır (Tablo-3). 
Tablo 3. Ülkelerin Makale Sayısı, SCP ve MCP Değerleri

\begin{tabular}{|c|c|c|c|c|c|}
\hline Ülke & Makale & Frekans & SCP & МCP & $\begin{array}{l}\text { MCP } \\
\text { Oran }\end{array}$ \\
\hline USA & 360 & 0.283688 & 330 & 30 & 0.0833 \\
\hline Germany & 128 & 0.100867 & 102 & 26 & 0.2031 \\
\hline $\begin{array}{l}\text { Turkey } \\
\text { Australıa }\end{array}$ & $\begin{array}{l}75 \\
72\end{array}$ & $\begin{array}{l}0.059102 \\
0.056738\end{array}$ & $\begin{array}{l}67 \\
66\end{array}$ & $\begin{array}{l}8 \\
6\end{array}$ & $\begin{array}{l}0.1067 \\
0.0833\end{array}$ \\
\hline United Kıngdom & 55 & 0.043341 & 50 & 5 & 0.0909 \\
\hline South Africa & 54 & 0.042553 & 48 & 6 & 0.1111 \\
\hline Netherlands & 49 & 0.038613 & 39 & 10 & 0.2041 \\
\hline Chına & 44 & 0.034673 & 36 & 8 & 0.1818 \\
\hline Israel & 36 & 0.028369 & 32 & 4 & 0.1111 \\
\hline New Zealand & 36 & 0.028369 & 32 & 4 & 0.1111 \\
\hline Sweden & 28 & 0.022065 & 22 & 6 & 0.2143 \\
\hline Malaysıa & 27 & 0.021277 & 23 & 4 & 0.1481 \\
\hline Canada & 25 & 0.019701 & 21 & 4 & 0.16 \\
\hline Spain & 25 & 0.019701 & 19 & 6 & 0.24 \\
\hline Korea & 23 & 0.018125 & 16 & 7 & 0.3043 \\
\hline Hong Kong & 17 & 0.013396 & 17 & 0 & 0 \\
\hline Norway & 17 & 0.013396 & 12 & 5 & 0.2941 \\
\hline Brazıl & 16 & 0.012608 & 6 & 10 & 0.625 \\
\hline Finland & 15 & 0.01182 & 13 & 2 & 0.1333 \\
\hline Thasland & 14 & 0.011032 & 11 & 3 & 0.2143 \\
\hline
\end{tabular}

Tablo-3 incelendiğinde sorumlu yazarın ülkeleri tablosunda makale sayısına göre ilk 20 ülke yer almaktadır. Tabloya göre makale sayısında ilk üç sırada yer alan ABD, Almanya ve Türkiye ilk sıralarda yer almasına rağmen düşük MCP oranına sahip oldukları tespit edilmiştir. Diğer bir deyişle araştırmacıların çoğunlukla aynı ülkedeki 
meslektaşlarıyla yayın yaptıkları dikkati çekmektedir. Brezilya 20 ülke içerisinde 18. sırada yer almasına rağmen MCP oranı en yüksek ülke olarak dikkat çekmektedir. Kore de MCP oranı yüksek olan ülkedir. Bu durum, Brezilya ve Kore'deki araştırmacıların uluslararası işbirlikçi çalışmalara daha açık olduklarını göstermektedir. MCP oranı en düşük ülkeler olarak Hong Kong, ABD ve Avustralya dikkati çekmektedir. Şekil-2'de ülkelerin makale üretimi gösterilmektedir.

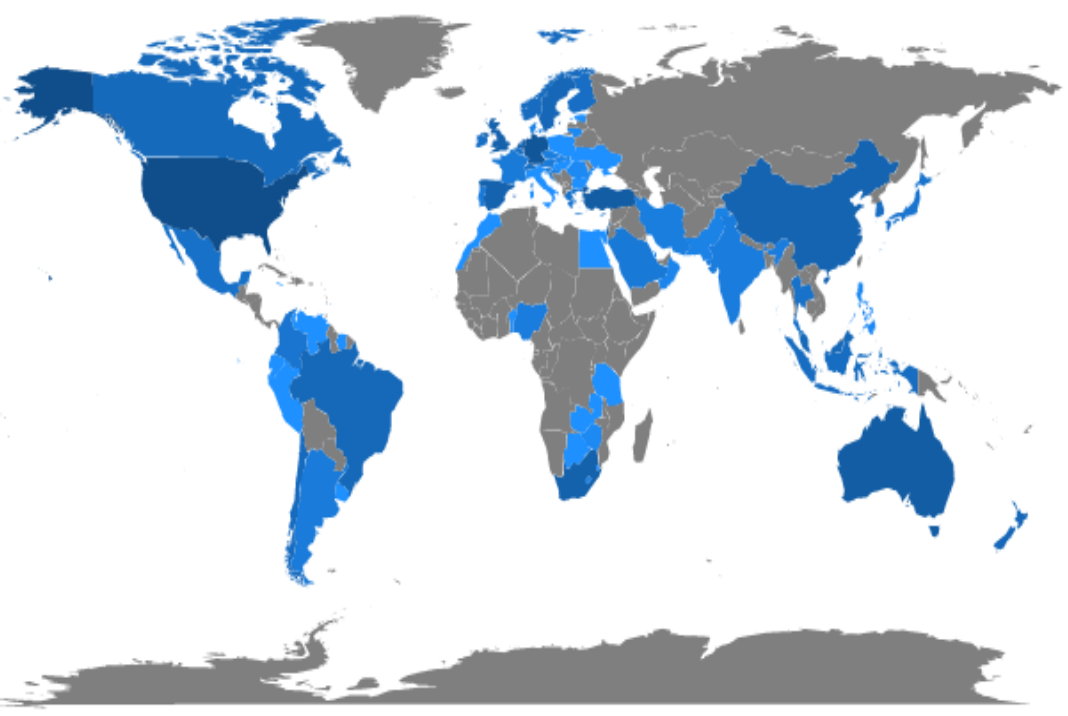

Şekil 2. Ülkelerin Bilimsel Üretkenliği

Şekil-2 incelendiğinde haritadaki koyu mavi renkten açık mavi renge doğru giden renkler yayın sayısını göstermektedir. Renk koyu maviden açık maviye doğru gittikçe yapılan makale sayısının azaladığı anlaşılmaktadır. Gri renkli olan ülkelerde ise veri tabanında taranan herhangi bir makale bulunmamaktadır. Haritanın nicel veri kısmı incelendiğinde toplamda 926 çalışmayla ABD, 374 çalışmayla Almanya ve 193 çalışmayla Türkiye ilk üç sırada yer almaktadır. Grafik-7'de en çok atıf yapılan ülkeler yer almaktadır. 


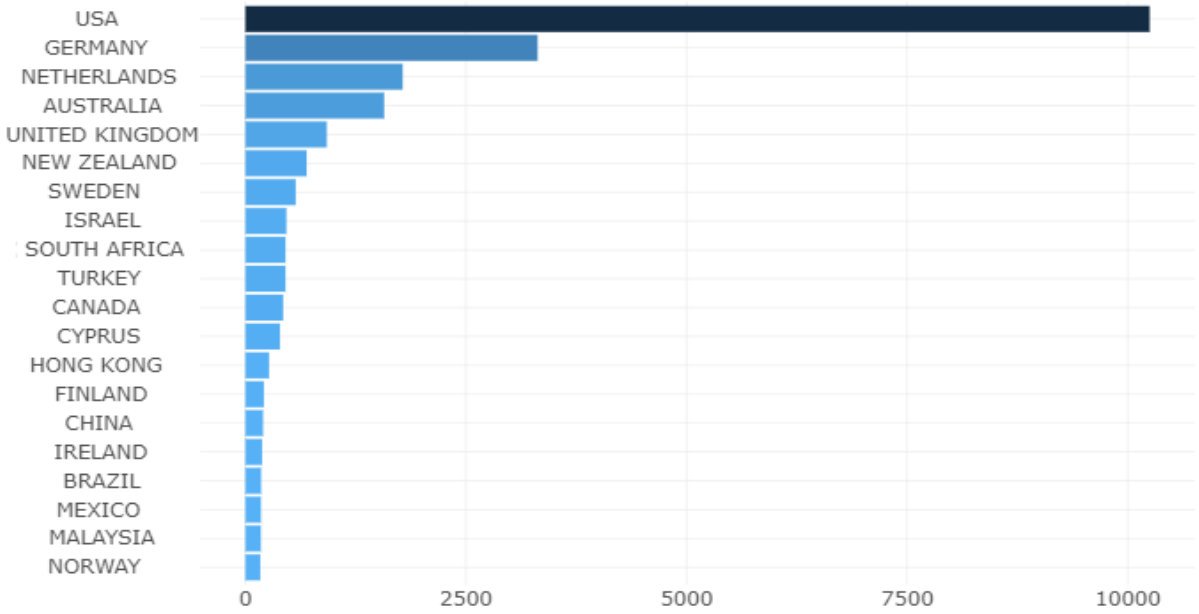

Grafik 7. En Çok Atıf Yapılan Ülkeler

Grafik-7 incelendiğinde konuyla ilgili olarak en çok atıf yapılan ülkelerin ABD (f= 10249), Almanya ( $f=3312)$ ve Hollanda $(f=1783$ ) olduğu görülmektedir. Grafik- 8 'de en fazla atıf yapılan çalışmalar yer almaktadır.

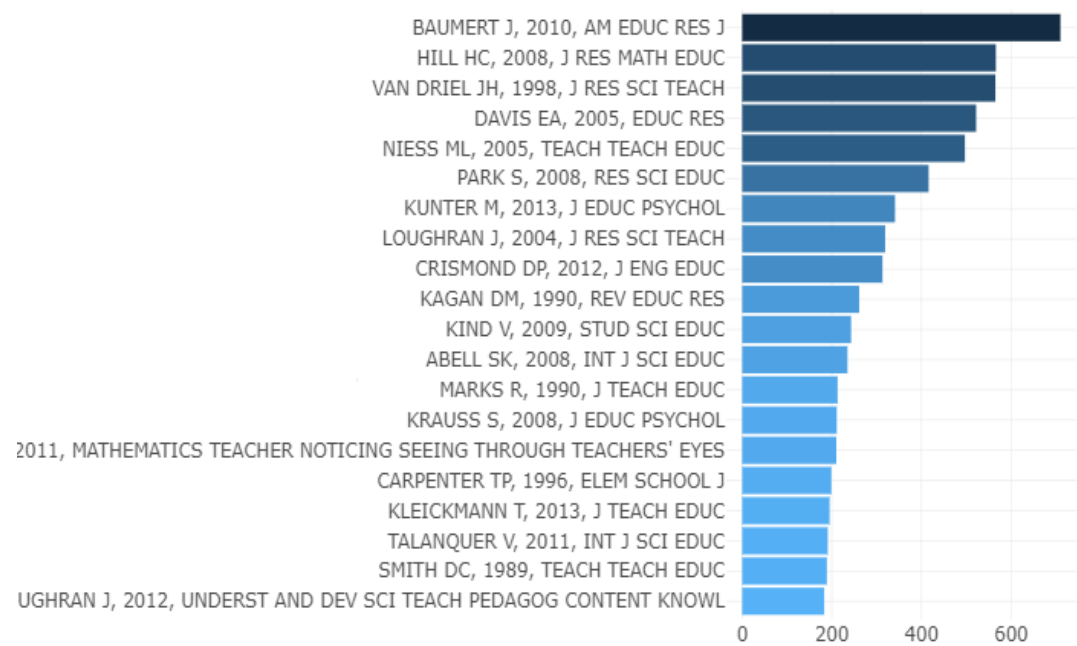

Grafik 8. En Fazla Atıf Alan Çalışmalar 
Grafik-8 incelendiğinde "PCK" anahtar kavramıyla ilgili küresel bazda en fazla atıf alan makaleler toplam 710 atıfla Baumert vd. (2010), 566 atıfla Hill (2008) ve 565 atıfla Van Driel vd. (1998)'in çalışmalarıdır. Şekil-3'te makalelerde en fazla kullanılan anahtar kavramlara ilişkin grafik yer almaktadır.

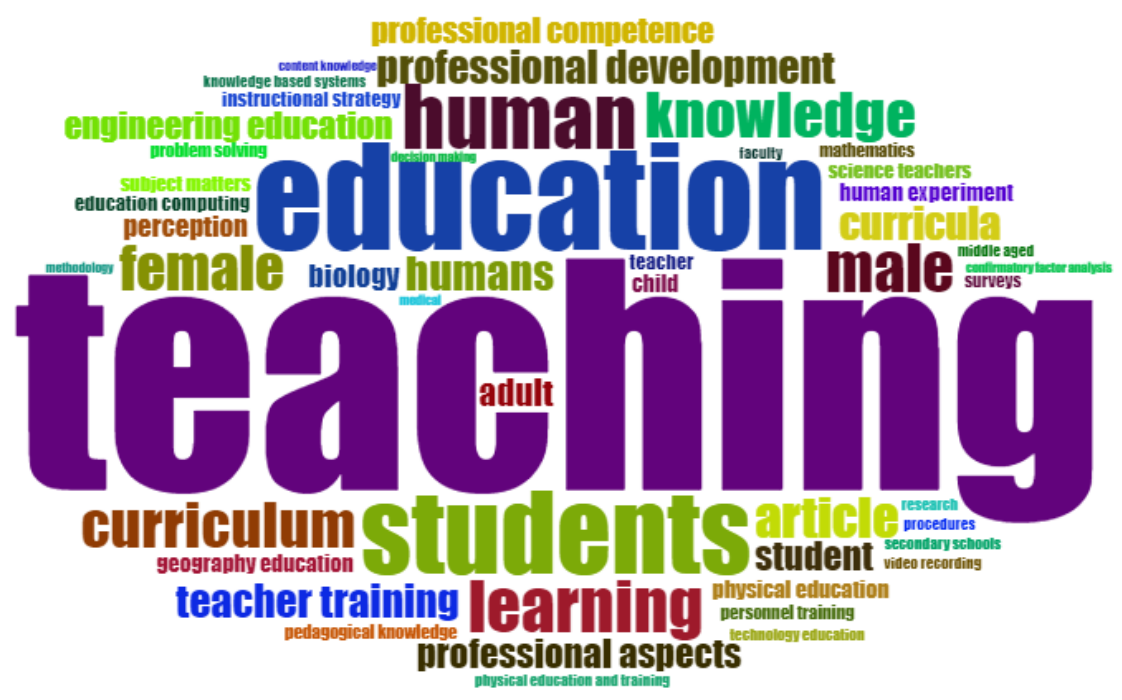

Şekil 3. Kelime Bulutu

Metin madenciliği yöntemlerinden birisi olan kelime bulutu (word clouds) bir metinde ya da paragrafta en çok kullanılan kelimeleri göstermektedir. Merkeze alınan kelime konu alanına özgü en fazla kullanılan kelimeyi göstermektedir. Kelimelerin boyutu ve merkeze yakınlığı, konu alanına özgü kullanılan kelimeleri göstermektedir. Kelime boyutu küçüldükçe ve merkezden uzaklaştıkça o kelimenin daha az kullanıldığına işaret etmektedir. Şekil-3 incelendiğinde en çok kullanılan anahtar kelimelerin teaching ( $f=119)$, pedagogical content knowledge $(f=64)$, education $(f=55)$, students $(f=43)$ ve human ( $\mathrm{f}=33)$ olduğu görülmektedir. Şekil-4'te ise makalelerin özet kısmında en çok kullanılan kelimeleri gösteren grafik yer almaktadır. 

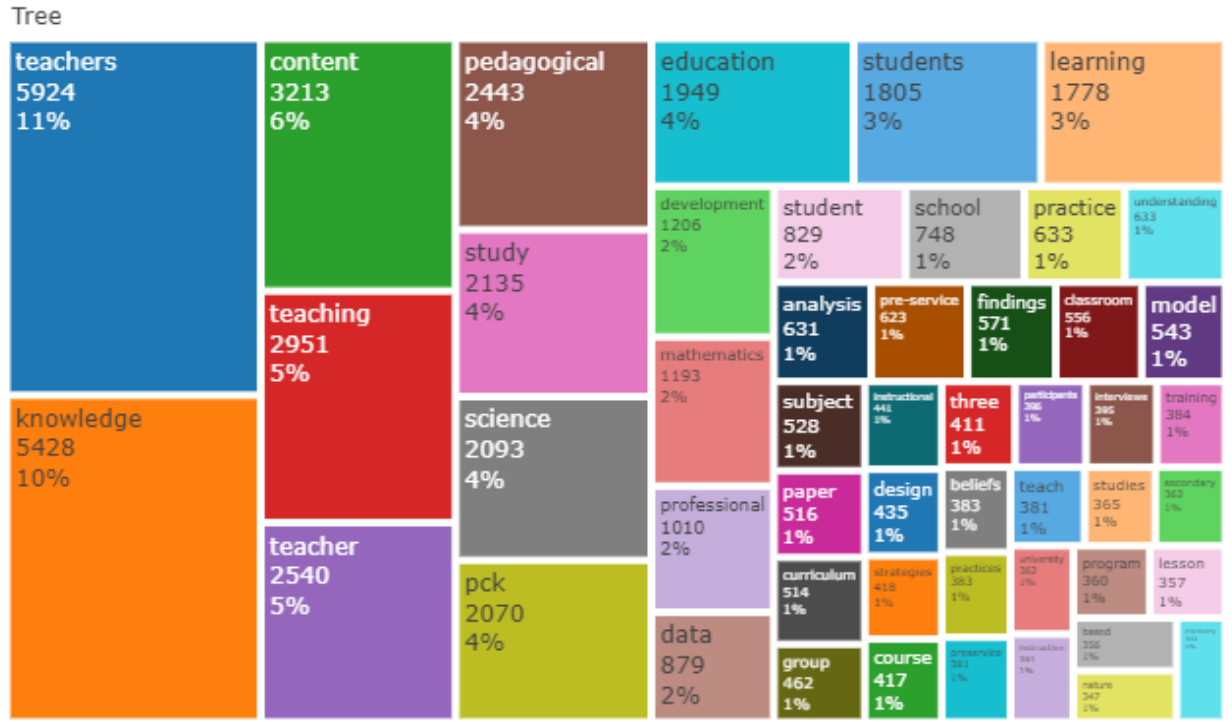

Şekil 4: Kelime Ağacı Haritası

Metin madenciliği yöntemlerinden bir diğeri de kelime ağacı haritasıdır (word tree map). Kelime ağacı haritası bir metinde ya da paragrafta en çok kullanılan kelimeleri göstermektedir. Şekil-4'te yer alan kelimeler PAB (PCK) ile ilgili makalelerin özet bölümünde en fazla kullanılan kelimeleri göstermektedir. Şekile göre en fazla kullanılan kelimeler; teachers $(\mathrm{f}=5924)$, knowledge $(\mathrm{f}=5428)$ ve content $(\mathrm{f}=3213)$ 'dir. Grafik-9 bu konuda araştırma yapan yazarların iş birliğini göstermektedir. 


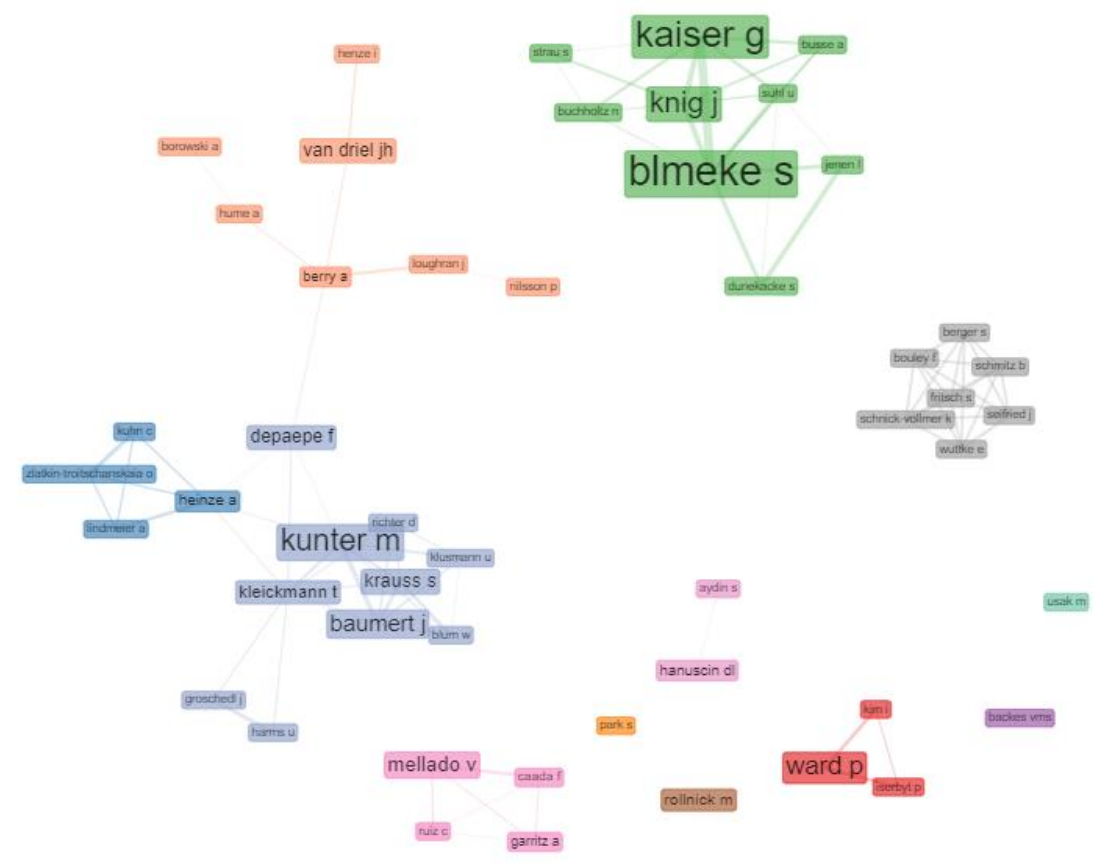

Grafik 9. Ortak İşbirliği Ağı

Grafik-9'a göre işbiliği yapan yazarların aynı kümede yer aldıkları görülmektedir. Aynı kümede yer alan yazarların benzer konuda yayınlar yaptığı ve birlikte çalıştıkları söylenebilir.

Tablo 4'te pedagojik alan bilgisi konu alanına yönelik olarak h-index sıralamasına göre ilk 20 'de yer alan yazarlar yer almaktadır. 
Tablo 4. Yazarların h-indeks Siralamaları

\begin{tabular}{|c|c|c|c|c|}
\hline & & & Makale & Yayına Başlama \\
\hline Yazar & h_index & Toplam Atıf & Sayısı & Yılı \\
\hline Blömeke S & 15 & 624 & 21 & 2011 \\
\hline Kaiser G & 11 & 428 & 19 & 2008 \\
\hline Berry A & 10 & 1098 & 11 & 2001 \\
\hline Van Driel JH & 9 & 1299 & 14 & 1998 \\
\hline Ward P & 9 & 233 & 14 & 2011 \\
\hline Kunter M & 9 & 1572 & 12 & 2008 \\
\hline Baumert J & 9 & 1691 & 9 & 2008 \\
\hline Knig J & 8 & 297 & 13 & 2011 \\
\hline Loughran J & 8 & 964 & 10 & 2001 \\
\hline Van Driel J & 8 & 330 & 9 & 2003 \\
\hline Rollnick M & 7 & 274 & 14 & 2008 \\
\hline Park S & 7 & 789 & 11 & 2008 \\
\hline Hanuscin DL & 7 & 262 & 10 & 2009 \\
\hline Nilsson P & 7 & 410 & 10 & 2008 \\
\hline Hume A & 7 & 230 & 9 & 2009 \\
\hline Davis EA & 7 & 749 & 7 & 2004 \\
\hline Suhl U & 7 & 267 & 7 & 2011 \\
\hline Kleickmann $\mathrm{T}$ & 6 & 317 & 8 & 2012 \\
\hline Krauss S & 6 & 1278 & 8 & 2008 \\
\hline Harms U & 6 & 127 & 7 & 2014 \\
\hline
\end{tabular}

h-indeksi, araştırmacıların yapmış oldukları bilimsel çalışmalarının kalitesinin değerlendirilmesine olanak sağlamaktadır. h-indeksi bir araştırmacının $\mathrm{h}$ adet makalesinden her birisi en az h kadar atıf almışsa ve diğer makaleleri de en fazla $h$ sayıda atıf almışsa bu araştırmacının indeks değerini h olarak ifade etmektedir (Hirsch, 2005). Tabloda yer alan 20 yazardan en erken üretime başlayan yazarın 1998 yılında ilk çalışmalarının yayınlandığı, en geç üretime başlayan yazarın ise 2014 yılında ilk 
çalışmalarını yayınladığı tespit edilmiştir. Son on sırada yer alan yazarların bir araştırmacı haricinde genel olarak daha yeni araştırmacılar olduğu görülmektedir. $\mathrm{Bu}$ araştırmacıların yayınlarına 2007'den sonra başladıkları görülmektedir.

\section{SONUÇ, TARTIŞMA ve ÖNERILER}

$\mathrm{Bu}$ çalışmada uluslararası yayınlara ve atıf indekslerine ulaşım sağlayan Scopus veri tabanında "pedagogical content knowledge" anahtar kavramı kullanılarak tarama yapılmıştır. Tarama sonucunda toplam 1760 çalışmaya ulaşılmıştır. Bu çalışmaların 1600 tanesi makale, 18 tanesi kitap ve 146 tanesi kitap bölümüdür. Yayın türü ve zaman aralığı kısıtlamaları yapılarak belirlenen toplam 1760 çalışma ile R-Studio programı kullanılarak bibliyometrik analiz yapılmıştır. Makalelerin yıllara göre dağılımına, bu konuda en çok yayın basan dergilere, en çok yayın yapan yazarlara, yazarların konu alanıyla ilgili olan $\mathrm{h}$ indeksine, ülkelerin bilimsel üretkenliğine, işbirliği ağlarına, ortalama alıntı sayısına, en çok atıf yapılan makalelere, yazarların atıf patlama değerlerine, metin madenciliği yöntemlerinden olan kelime bulutu ve kelime ağacı yapılarına ulaşılmıştır.

Araştırmanın sonuçlarına göre veri tabanında yer alan en eski makalenin 1987 yılında yayınlandığı tespit edilmiştir. "Scandinavian Journal of Educational Research" dergisinde yayınlanan "Pedagogical Content Knowledge in Social Studies" başlıklı bu makale S. Gudmundsdottir ve L. Shulman tarafından yazılmıştır. Yıllara göre çalışma sayısında dalgalanmalar yaşansa da en fazla çalışma üretiminin 2017-2020 yılları arasında gerçekleştiği belirlenmiştir $(\% 10,48)$. Bu konuda en fazla çalışmanın 2020 yılında ( $\mathrm{f}=185$ ) yapıldığı tespit edilmiştir. Konu alanına yönelik yıllık çalışma üretim oranın \%17.8 olduğu tespit edilmiştir. Yıllık artış oranına (Annual growth rate) bakıldığında 2021 yılında konu alanına yönelik makale sayısında bir artış olacağı ve bu yılın makale sayısında ilk sırada yer alacağı öngörülmektedir. Bu durum pedagojik alan bilgisi araştırmalarının her zaman güncelliği koruyacağının bir göstergesi olarak yorumlanabilir. 
Bu konuda yayınlanan çalışmaların 566 farklı kaynakta yayınladığı tespit edilmiştir. Bu durum konu alanına önem verdiğinin göstergesidir. Bu konuda en fazla makale basan derginin "International Journal of Science Education" olduğu belirlenmiştir ( $\mathrm{f}=66$ ). Listedeki diğer dergilerin de pedagojik alan bilgisine yönelik makalelere yer verdiği ve alandaki prestijli dergiler olduğu görülmektedir. Konu alanıyla ilişkili olarak bireysel ya da işbirliği içinde toplam 3248 yazarın çalışma yaptığı tespit edilmiştir. Konu alanına yönelik en fazla yayın yapan ve h-indeksi en yüksek olan (15) yazar S. Blömeke'dir. Araştırmacının Scopus veri tabanında bu konuda 21 makalesi, 624 atıfı bulunmaktadır. Hemen ardından gelen araştırmacı ise h-indeksi 11 olan G. Kaiser'dir. Araştırmacının bu konuda yayınladığı 19 makalesi, bu makalelere aldığı 428 atıfı bulunmaktadır. İki araştırmacı ararştırmalarının büyük bir çoğunluğunu işbirliği içinde gerçekleştirmiştir. Bu çalışmalarının matematik eğitimi alanında konular açısından çeşitlilik gösterdiği son yıllarda daha çok öğretmen bilgi, kaygı, inaç ve becerileri arasındaki ilişki üzerine olduğu görülmektedir. Listede yer alan yazarlardan yayına başlama zamanı eski olanların zaman içerisinde yeni çalışma yapma ihtimalleri daha fazladır. Çünkü bu yazarların yetiştirdiği araştırmacılar ve farklı çalışmalar sonucunda oluşturdukları çalışma gruplarıyla yayın yapma ihtimalleri yeni başlayan diğer yazarlara göre daha yüksektir. Ancak yeni yazarların da zaman geçtikçe atıf alma oranı artacağı için ilerleyen yıllarda eski araştırmacılara göre indeks sırasının yükseleceği öngörülmektedir.

Pedagojik alan bilgisi araştırmaları en fazla Amerika, Almanya ve Türkiye’deki araştırmacıların ilgisini çekmiş, en fazla yayın yapan araştırmacıların bu ülkelerde oldukları tespit edilmiştir. Pedagojik alan bilgisi konusunda Türkiye yayın sayısı sıralamasında 3. olmasına rağmen atıf yapılan ülkeler sıralamasında daha gerilerde yer almıştır. Bibliyomertrik analizler eserlerin konu içerikleri hakkındaki verilerden değil bibliyometrik özelliklerinden yararlanılarak gerçekleştirilir bu nedenle elde edilen bu sonuç ile ilgili olarak doğrudan yayın içerikleri ilgili bir çıkarsama bulunulamaz ancak bu durumun nedeni olarak Türkiye'de gerçekleştirilen araştırmaların uluslararası araştırma eğiliminden uzakta olmasından ya da daha spesik konularda çalışmalar 
gerçekleştirilmesinden kaynaklanıyor olabilir. Pedagojik alan bilgisi konusundaki çalışmalarda Brezilya ve Kore'deki araştırmacılar ise uluslararası işbirliğe en açık araştırmacılardır. Brezilyalı araştırmacıların Meksika, İspanya, Portekiz gibi ülkelerdeki araştırmacılarla ortak yayınlar yaptıkları belirlenmiştir (Örneğin; Backes, Moya ve Prado, 2011; Marcon, Graça ve Nascimento, 2012). Koreli araştırmacıların ise daha çok ABD, Avustralya ve Finlandiya gibi ülkelerdeki meslektaşlarıyla çalıştıkları tespit edilmiştir (Örneğin; Lee, Chu ve Martin, 2018; Park, Choi ve Reynolds, 2020).

Yıllık ortalama alıntı sayısı en fazla olan yıl 1998'dir. Atıf patlama değerine göre, en çok atıf alan araştırmacı 2013 yılında yayınlanan çalışmalarıyla J. Baumert ve M. Kunter olmuştur. Atıf patlama değerine göre ilk sırada yer almasını sağlayan çalışmaları; “Journal of Educational Psychology” dergisinde yayınlanan "Professional competence of teachers: Effects on instructional quality and student development" başlıklı makaleleridir. Bir eserin atıf patlamasına sahip olması en çok atıfı almasını gerektirmemektedir. Atıf patlaması için dönemsel atıf yoğunluğuna odaklanılır. Dolayısıyla atıf patlaması Scopus’ta incelenen 1760 çalışmanın kaynakçalarındaki belli zaman aralıklarında en fazla atıf almış çalışmalara göre şekillenir. Bu yazarlardan sonra atıf patlama sıralamasında üçüncü sırada atıf patlamasına sahip çalışması ise 2012 yılında yayına çıkan “Understanding and Developing Science Teachers' Pedagogical Content Knowledge" başlıklı kitabıdır. Ancak bu yazarın yaptığı çalışma Baumert ve Kunter'in atıf patlama değerini geçememiştir. Bu konuda en fazla atıf alan makale 2010 yılında "American Educational Research Journal” dergisinde yayınlanan "Teachers' Mathematical Knowledge, Cognitive Activation in the Classroom, and Student Progress" başlıklı makale olup, Baumert vd. tarafından yazılmıştır.

Kelime bulutu ve kelime ağacı haritası yöntemleri kullanılarak elde edilen verilere göre hem bu konuda tarama yaparken kullanılan anahtar kelimeler, hem de özet bölümünü yazarken araştırmacıların en fazla kullandığı kavramlar "teaching/(öğretim)" ve “teachers/(öğretmenler)" kavramları olmuştur. "Knowledge(bilgi)" ve "education(eğitim)" kavramlarının da araştırmacılar tarafından özet ve anahtar kelimeler bölümlerinde oldukça sık kullanıldığı görülmektedir. Veri tabanlarının taranmasında 
kullanılan diğer anahtar kelimer, disiplinleri (matematik, fizik, biyoloji, kimya, mühendislik eğitimi, coğrafya eğitimi) veya odaklanmış örnek grupları (öğrenci ve öğretmen, öğretmen adayı), pedagojik alan bilgisinin bileşenlerileri (örneğin, öğretim stratejileri, öğretim programı, değerlendirme) ve aynı zamanda pedagojik alan bilgisiyle ilişkili profesyonel kelimesiyle nitelendirilmiş profesyonel yeterlilik, profesyonel bakışaçısı, profesyonel gelişim kavramlarını içermektedir.

$\mathrm{Bu}$ çalışmanın bulgularından hareketle, bu alanda daha ileri araştırmalar için bazı önerilerde bulunulabilir:

- Pedagojik alan bilgisi araştırmaların sayısının yaklaşık olarak dönem yıl bazında artış gösteriyor olması öğretmenlik mesleği varoldukça bu çalışma alanının önemini koruyacağının bir göstergesi olarak yorumlanabilir. Araştırmacıların bu konuda çalışmalarını sürdürmeleri önerilmektedir.

- Bibliyometrik analiz, araştırmacıların araştırma alanları seçmelerine ve yürütmelerine yardımcı olur. Bu çalışma, genel olarak tüm disiplinlerdeki pedagojik alan bilgisi araştırmalarını kapsamaktadır. Araştırmacılar, sınırlandırma yaparak disiplin temelinde temel araştırmaları tanımak ve ayrıca bu yayınlardan yararlanmak için çeşitli anahtar kelimeler kullanarak biyometrik analizler yapabilirler. Ek olarak, araştırmalarını yayınlamada ilgilli dergileri belirleyebilirler.

- Bu çalışmada Scopus veritabanı indeksi kullanılmıştır. R Studio programı yalnızca Scopus ve Web of Science Core Collection veritabanları ile kullanılmak üzere tasarlanmıştır. WOS, ProQuest, YÖK TEZ gibi diğer indeksler kullanılarak da bibliyometrik araştırmalar gerçekleştirilebilir.

- Çalışmanın örnekleminde yer alan yayın türü makale, kitap ve kitap bölümleri ile sınırlıdır. Analizlerde tez ve konferans bildirisi gibi diğer yayın türleri kullanılarak araştırmalar gerçekleştirilebilir ya da farklı sınırlamalar kullanılarak daha odak çalışmalar gerçekleştirilebilir. Örneğin, yalnızca belirli dergilerde veya belirli dönemlerde yayınlanan makalelerin analizleri yapılabilir. 


\section{KAYNAKLAR}

Abell, S. K. (2008). Twenty years later: does pedagogical content knowledge remain a useful idea? International Journal of Science Education, 30(10), 1405-1416.

Abell, S. K. (2007). Research on science teachers' knowledge. In S.K. Abell ve N.G. Lederman (Eds.), Handbook of research on science education (s. 1105-1149). Mahwa, New Jersey: Lawrence Erlbaum Associates.

Al, U., Soydal, İ., \& Yalçın, H. (2010). Bibliyometrik özellikleri açisindan Bilig'in değerlendirilmesi. Bilig, Güz, 55, 1-20.

Aman, V., \& Botte, A. (2017). A bibliometric view on the internationalization of European educational research, European Educational Research Journal, 16(6) $843-868$

An, S., Kulm, G., \& Wu, Z. (2004). The pedagogical content knowledge of middle school, mathematics teachers in China and the US. Journal of mathematics teacher education, 7(2), 145-172.

Aria, M. \& Cuccurullo, C. (2017). Bibliometrix: An R-tool for comprehensive science mapping analysis. Journal of Informetrics, 11(4), 959-75.

Ball, D. L., Thames, M. H., \& Phelps, G. (2008). Content knowledge for teaching: What makes it special. Journal of teacher education, 59(5), 389-407.

Baumert, J., Kunter, M., Blum, W., Brunner, M., Voss, T., Jordan, A., ... \& Tsai, Y. M. (2010). Teachers' mathematical knowledge, cognitive activation in the classroom, and student progress. American educational research journal, 47(1), 133-180.

Berg, T., \& Brouwer, W. (1991). Teacher awareness of student alternate conceptions about rotational motion and gravity. Journal of Research in science teaching, 28(1), 3-18.

Backes, V. M. S., Moyá, J. L. M., \& Prado, M. L. D. (2011). The construction process of pedagogical knowledge among nursing professors. Revista latino-americana de enfermagem, 19(2), 421-428.

Carlsen, W. (1999). Domains of teacher knowledge. In Examining pedagogical content knowledge (pp. 133-144). Springer, Dordrecht.

Cochran, K. F., Deruiter, J. A., \& King, R.A. (1993). Pedagogical content knowing: an integrative model for teacher preparation. Journal of Teacher Education, 44(4). 263-272.

Cochran, K. F., King, R. A. \& DeRuiter, J. A. (1991). Pedagogical content knowledge: A Tentative Model for Teacher Preparation. Paper presented at the annual meeting of the American Educational Research Association, Chicago. (ERIC Document Reproduction Service NO. ED 340 683). 
Cooper, R., Loughran, J., \& Berry, A. (2015). Science teachers’ pck. Berry, A., Friedrichsen, P. \& Loughran, J., Re-examining Pedagogical Content Knowledge in Science Education, 60-74.

De Jong, O., \& Van Driel, J. (2004). Exploring the development of student teachers' PCK of the multiple meanings of chemistry topics. International Journal of Science and Mathematics Education, 2(4), 477-491.

Drechsler, M., \& Van Driel, J. (2008). Experienced teachers' pedagogical content knowledge of teaching acid-base chemistry. Research in Science Education, 38(5), 611-631.

Doğru, M., Güzeller, C. O., \& Çelik, M. (2019). A bibliometric analysis in the field of sustainable development and education from past to present. Adlyaman University Journal of Educational Sciences, 9(1), 42-68.

Even, R. (1993). Subject-matter knowledge and pedagogical content knowledge: Prospective secondary teachers and the function concept. Journal for Research in Mathematics Education, 24(2), 94-116.

Fix, J., Odell, J., Sina, B., Meslin, E. M., Goodman, K., \& Upshur, R. (2013). A Bibliometric Analysis of an International Research Ethics Trainee Program. Journal of Empirical Research on Human Research Ethics, 8(5), 7581. https://doi.org/10.1525/jer.2013.8.5.75

Friedrichsen, P. M., \& Dana, T. M. (2003). Using a card-sorting task to elicit and clarify science-teaching orientations. Journal of Science Teacher Education, 14(4), 291309.

Gess-Newsome, J. (1999). Pedagogical content knowledge: an introduction and orientation. Gess-Newsome, J., \& N. G. Lederman (Eds.), Examining pedagogical content knowledge (s.3-17). Dordrecht: Kluwer.

Grossman, P. L. (1990). The making of a teacher: teacher knowledge and teacher education. New York: Teachers College Press.

Güzeller, C. O. \& Çeliker, N. (2017). Gastronomy from past to today: A bibliometric analysis. Journal of Tourism and Gastronomy Studies, 5/Special Issue2, 88-102.

Huang, Y. L., Ho, Y. S., \& Chuang, K. Y. (2006). Bibliometric analysis of nursing research in Taiwan 1991-2004. Journal of Nursing Research, 14(1), 75-81.

Hill, H. C., Ball, D. L., \& Schilling, S. G. (2008). Unpacking pedagogical content knowledge: Conceptualizing and measuring teachers' topic-specific knowledge of students. Journal for research in mathematics education, 39(4), 372-400.

Kunter, M., Klusmann, U., Baumert, J., Richter, D., Voss, T., \& Hachfeld, A. (2013). Professional competence of teachers: Effects on instructional quality and student development. Journal of educational psychology, 105(3), 805.

Kurtuluş, M. A., \& Bilen, K. A bibliometrıc analysıs on nature of science: a review of the research between 1986-2019. Scientific Educational Studies, 5(1), 47-65 
Kurtuluş, M. A., \& Tatar, N. (2021) An Analysis of Scientific Articles on Science Misconceptions: A Bibliometric Research. Elementary Education Online, 20(1), 192-207.

Kurtuluş, M.A. \& Tatar, N. (2021). A bibliometrical analysis of the articles on environmental education published between 1973 and 2019. Journal of Education in Science, Environment and Health (JESEH), 7(3), 243-258. https://doi.org/10.21891/jeseh.960169

Lee, E., \& Luft, J. A. (2008). Experienced secondary science teachers' representation of pedagogical content knowledge. International Journal of Science Education, 30(10), 1343- 1363.

Lee, Y. J., Chu, H. E., \& Martin, S. N. (2018). Examining Factors that Influence on Elementary Teachers' Perceptions in a Graduate Level Interdisciplinary Environmental Education Program: Using ePCK as a Framework. EURASIA Journal of Mathematics, Science and Technology Education, 14(10), em1574.

Lin, Z., \& Lei, L. (2020). "The Research Trends of Multilingualism in Applied Linguistics and Education (2000-2019): A Bibliometric Analysis" Sustainability 12, no. 15: 6058. https://doi.org/10.3390/su12156058

Lopes, R. M., Fidalgo-Neto, A. A., \& Mota, F. B. (2017). Facebook in educational research: A bibliometric analysis. Scientometrics, 111(3), 1591-1621.

Loughran, J. J., Mulhall, P., \& Berry, A. (2004). In search of pedagogical content knowledge in science: Developing ways of articulating and documenting professional practice. Journal of Research in Science Teaching, 41(4),370-391.

Loughran, J., Berry, A., \& Mulhall, P. (2006). Understanding and developing science teachers' pedagogical content knowledge. Netherlands: Sense Publisher

Magnusson, S., Krajcik, J., \& Borko, H. (1999). Nature, sources and development of pedagogical content knowledge for science teaching. J. Gess-Newsome \& N.G. Lederman (Eds.), Examining Pedagogical Content Knowledge (s. 95-132). Dordrecht, Netherlands: Kluwer Academic Publishers.

Marcon, D., Graça, A. B. D. S., \& Nascimento, J. V. D. (2012). Pedagogical practices as scenery for the construction of pedagogical content knowledge of prospective physical education teachers. Revista da Educação Física/UEM, 23(2), 295-306.

Marks, R. (1990). Pedagogical content knowledge: from a mathematical case to a modified conception. Journal of Teacher Education, 41(3), 3-11.

Mavhunga, M. E. \& Rollnick, M. (2011). The development and validation of a tool for measuring topic specific pck in chemical equilibrium. Proceedings of Ninth ESERA-Conferance 2011, Lyon.

Mavhunga, E., \& Rollnick, M. (2013). Improving PCK of chemical equilibrium in preservice teachers. African Journal of Research in Mathematics, Science and Technology Education, 17(1-2), 113-125 
Mishra, P., \& Koehler, M. J. (2006). Technological pedagogical content knowledge: A framework for teacher knowledge. Teachers college record, 108(6), 1017-1054.

Monet, J. A. (2006). Examining topic-specific PCK as a conceptual framework for inservice teacher professional development in earth science. Unpublished Doctoral Dissertation, The State University of New Jersey, New Brunswick.

Morine-Dershimer, G., \& Kent, T. (1999). The complex nature and sources of teachers' pedagogical knowledge. In Examining pedagogical content knowledge (pp. 2150). Springer, Dordrecht.

Nilsson, P., \& Loughran, J. (2012). Developing and assessing professional knowledge as a science teacher educator: Learning about teaching from student teachers. In Self-studies of science teacher education practices (pp. 121-138). Springer, Dordrecht.

Park, S., Choi, A., \& Reynolds, W. M. (2020). Cross-national investigation of teachers' pedagogical content knowledge (PCK) in the US and South Korea: what proxy measures of teacher quality are related to PCK? International Journal of Science Education, 42(15), 2630-2651.

Rollnick, M., \& Mavhunga, E. (2014). PCK of teaching electrochemistry in chemistry teachers: A case in Johannesburg, Gauteng Province, South Africa. Educación química, 25(3), 354-362.

Sande, M.E. (2010). Pedagogical content knowledge and the gas laws: a multiple case study. Doctoral Dissertation, University of Minnesota, Minneapolis.

Shulman, L. (1986). Those who understand: knowledge growth in teaching. Educational researcher, 15(2), 4-14.

Shulman, L.S. (1987). Knowledge and teaching: foundations of the new reform. Harvard educational review, 57(1), 1-22.

Tamir, P. (1988). Subject matter and related pedagogical knowledge in teacher education. Teaching and teacher education, 4(2), 99-110.

Taner, M.S., Kurtulus, M.A. \& Bilen, K. (2021). A Bibliometric Research on Astronomy Education in Turkey and The Worldwide. Turkish Journal of Teacher Education, 10(1), 23-39.

Van Driel, J. H., Verloop, N., \& De Vos, W. (1998). Developing science teachers' pedagogical content knowledge. Journal of Research in Science Teaching: The Official Journal of the National Association for Research in Science Teaching, 35(6), 673-695.

Veal, W. R., \& MaKinster, J. G. (1999). Pedagogical content knowledge taxonomies. The Electronic Journal for Research in Science \& Mathematics Education. 


\section{ORCID}

Mücahit KÖSE ${ }^{D}$ https://orcid.org/0000-0002-1938-6092 


\section{SUMMARY}

\section{Purpose}

The aim of this study is to introduce the leading researchers working on pedagogical content knowledge and their publications found in the literature on this subject, along with the keywords frequently used for the subject search associated with pedagogical content knowledge.There is no such work in the literature on this subject, and it is believed that the results will provide indepth understanding of the pedagocigal content knowledge and set a guideline for future studies related to this subject. For this purpose, 34 years of pedagogical content knowledge research between 1987-2020 is analyzed through bibliometric research.

\section{Method}

The descriptive research model has been adopted for this bibliometric study and the bibliometric properties of the articles, books, and book chapters are determined by using the keyword of "Pedagogical content knowledge" in the Scopus database. The research data consists of articles, and book chapters related to the key concepts of "pedagogical content knowledge" published in different journals and books between 1987-2020 in the Scopus database. The most important data sources considered in bibliometric studies are international citation indexes such as Science Citation Index (SCI), Social Science Citation Index (SSCI), and Art \& Humanities Citation Index (A \& HCI). In this study, a search is done with the key concepts of "Pedagogical content knowledge" and a total of 2024 studies were obtained from the database. In the context of the purpose of the study, 1760 articles, books, and book chapters were addressed with the restriction dependin on the type of publications andtheir publishing date. The R-Studio program has been employed in order to scan the publications obtained within the scope of this research.

\section{Findings}

In this research, investigation on a total of 1760 publications on Pedagogical content knowledge is provided. It is seen that the first article related to PCK published in 1987, and most publications in the related field were found between 2017-2020 $(f=645)$. It should be noted that the works published after 2011 constitute $72.85 \%$ of the total. It is also observed that the average number of citations for the subject area was the most in 1998. By scanning the key concept of "Pedagogical Content Knowledge", it is noticed that the International Journal of Science Education $(f=66)$, Journal of Science Teacher Education $(f=52)$, and Teaching and Teacher Education $(f=49)$ are the journals which have published most number of articles That the total of 1760 publications were made, either collaboratively or individually, related to this subject is another remarkable finding obtained from this study. When we look at the number of articles per author, it was found that the rate was 0.543, and when the number of authors per article was examined, it was found that the authors who wrote the most articles on PCK were S. Blömeke $(f=$ 21), G. Kaiser $(f=19)$ and M. Rollnick $(f=14)$. Among the authors, those with the highest citation burst were M. Kunter (60.89) between the years 2008-2020 and J. Baumert between the years 2008-2015. When the countries of the responsible authors are examined, the section called 
SCP (Single Country Publications) shows the number of publications made by researchers in the same country, and the section called MCP (Multiple Country Publications) shows the publications made by researchers from more than one country. Considering the countries of the responsible authors, the USA (SCP: 330, MCP: 30) with 360 articles, Germany (SCP: 102, MCP: 26) with 128 articles, and Turkey (SCP: 67, MCP: 8) with 75 articles are in the top three. It is noteworthy that although the USA, Germany, and Turkey, which are in the first three places in the number of articles, they have low MCP rates, they mostly publish with their colleagues in the same country. Although Brazil ranks 18th among 20 countries, it draws attention as the country with the highest MCP rate. Korea is the country with a high MCP rate. It has been determined that the most cited countries are the USA $(f=10249)$, Germany $(f=3312)$, and the Netherlands $(f=1783)$. The most frequently cited articles on the key concept of "PCK" on a global basis, with a total of 710 citations, were published by Baumert et al. (2010), Hill (2008) with 566, and Van Driel et al. (1998) 's work. It is seen that the most used Key concepts are "teaching" ( $f=119)$, "pedagogical content knowledge" ( $f=64)$, "education" ( $f=55)$. The authors with the highest $H$ index were determined as Blömeke $S$, Kaiser G, Berry A.

\section{Discussion and Conclusion}

In this study, the Scopus database, which provides access to international publications and citation indexes, was scanned by using the key concepts of "pedagogical content knowledge". As a result of the scanning, a total of 1760 studies were found. 1600 of these studies are articles, 18 of them are books and 146 of them are book chapters. By using the R-Studio program, bibliometric analysis was performed with a total of 1760 studies by restricting them based on the type of publication and publishing date.

According to the results of this research, it was determined that the oldest article found in the database was published in 1987. This article titled "Pedagogical Content Knowledge in Social Studies" published in Scandinavian journal of Educational Research "was written by S. Guudmundsdottir and L. Shulman. Although there were fluctuations in the number of work by years, it was determined that the highest work production was realized between 2017-2020 $(36.65 \%)$. It was indicated that most studies on this subject were carried out in $2020(f=331)$. It has been shown that the annual production rate for the subject area is $17.8 \%$. Considering the annual growth rate, it is predicted that there will be an increase in the number of articles on the subject area in 2021 and will rank first in the number of articles this year. This situation can be interpreted as an indication that Pedagogical content knowledge research will always be up-todate. It was determined that a total of 3248 authors worked individually or in collaboration about pedagogical content knowledge. The author who publishes the most in the subject area and has the highest $h$ index (15) is S.Blömeke. The researcher has 21 articles and 624 citations in the Scopus database. The next researcher is G. Kaiser with an $H$ index of 11. The researcher has 19 articles published on this subject and 428 references to these articles. These two researchers collaborated with each other in the vast majority of their research. Although it is determined that these studies vary in terms of subjects in the field of mathematics education, it has been observed that in recent years, it has been mostly on the relationship between teacher knowledge, anxiety, belief, and skills. Among the authors on the list, those whose publication time is old are more 
likely to make new studies over time. Because these authors are more likely to publish with the researchers they have trained and the working groups they have created as a result of different studies than other newcomers. However, as the rate of citation of new authors will increase as time passes, it is predicted that the index order will increase compared to previous researchers in the following years. 